\title{
Demography factors, financial risk tolerance, and retail investors
}

\author{
Bertha Silvia Sutejo, Yohanes Kokoh Natan Pranata \& Putu Anom Mahadwartha \\ University of Surabaya, Surabaya, Indonesia
}

\begin{abstract}
This study aims to understand the influence of demography factors, as an independent variable to the financial risk tolerance of retail investors who conduct stock investment transactions on the Indonesia Stock Exchange, as a dependent variable. The research used a quantitative approach to binary logistic regression analysis model and online questionnaire method for the data collection. The questionnaires were distributed through online media and communication tools, including the mailing list and social media. The number of observed respondents which met the criteria were about 162 respondents. Then, the parametric study showed a significant positive partial effect from the independent variable, income, against dependent variable financial risk tolerance. The other independent variables consisted of gender, age, marital status, education, and occupation; did not exhibit any significant impact on financial risk tolerance.
\end{abstract}

Keywords: demography factors, financial risk tolerance, retail investors.

\section{INTRODUCTION}

Investors have different behaviors in making calculation or assessments as a basis for investment decisions. This investor behavior plays the biggest role in investing. Investor behavior itself is closely related to the Financial Risk Tolerance (FRT) defined by Grabble et al. (2006) as the willingness of individual investors to receive negative changes of investment value or the result opposite or different from the expected results.

An understanding of risk tolerance plays an important role in every optimal portfolio decision (Sulaiman 2012). This is reinforced by the argument from Hanna et al. (2001) that utters the FRT plays a crucial part for individual investors regarding the collection of wealth, pension funds, portfolio allocations, insurance and other investments that depends on this behavior. Furthermore, Moreschi (2004) assumes that understanding and assessing FRT is one of the most influential steps to make optimal riskreward trade-off decisions. Kannadhasan (2015) suggests that choosing a portfolio that is inconsistent with risk tolerance will result in disappointment from investors and make investors experiencing financial stress.

Demographic factors from individual investors can be used to determine the level of financial risks and associations of these variables can be developed to predict investor risk tolerance (Sulaiman 2012). Chang et al. (2004) also mention that in practice, demographic factors can be used to differentiate and classify retail investors, and help to develop better financial strategies. Examples of demographic factors are gender, age, status, income, occupation, education, and so on.

Kannadhasan (2015) shows the role of demographic factors to differentiate retail investors into Financial Risk Tolerance (FRT) and Financial Risk Behavior (FRB) of 778 respondents in Raipur, Chhattisgarh, India on January and February 2013. Using 6 variables independent (gender, age, marital status, education, occupation, income) and 2 dependent variables (Financial Risk Tolerance, Financial Risk Behavior), the result shows some demographic factors that significantly play a role in determining FRT and FRB levels are gender, age, education, and occupation, while the marital status and incomes do not contribute in the differentiation of FRT and FRB levels.

Sulaiman (2012) examines the empirical analysis of the financial risk tolerance and demographic features of individual investors of 300 respondents working at two universities, the University of Kerala and Mahatma Ghandi University in India in 2010. Using 6 independent variables (gender, age , marital 
status, education, annual income, number of dependants) and 1 dependent variable (Financial Risk Tolerance), it is found that the demographic features or factors that play a significant role in determining FRT are age, marital status, education, annual income, and number of dependants. Another factor of gender is independent against FRT.

Thanki (2015) also finds a correlation between demographic characteristics with risk tolerance and personality type with risk tolerance in 258 respondents in the city of Ahmedabad, India. By using 6 independent variables (gender, marital status, age, income, education, occupation, personality type) and 1 dependent variable (Risk Tolerance), it is found that women have tendency as risk-averse, unmarried investor taking higher risk, the investor with the age of 25 to 45 years has the lowest risk tolerance, the positive correlation between income and risk tolerance, no correlation between education with risk tolerance, the investor who owns the business possesses a higher risk tolerance, and the A personality type that is more aggressive, impatient takes a higher risk than the $\mathrm{B}$ personality type.

Based on the above findings, this research is motivated to examine the influence of demographic factors of retail investors (gender, age, marital status, education, employment and income) to Financial Risk Tolerance (FRT) or financial tolerance level in Indonesia. The financial risk tolerance to be studied focuses on tolerance to stock investments only.

\section{RESEARCH METHODS}

This study is a descriptive conclusive research using quantitative approach with 1 dependent variable, namely financial risk tolerance and 6 independent variables, namely gender, age, marital status, education, occupation, and income. The object of research is retail investors who conduct stock investment transactions on the Indonesia Stock Exchange with criteria: the minimum age of retail investors is 17 years, active in buying and selling stocks over the past 6 months, have a basic knowledge of stock investments by joining the group or discussion forum about stock transaction, and minimum of 1 stock transaction per month. The research questionnaire adapted Kannadhasan (2015) research using 1-4 Likert scale. The validity and reliability testing are done by looking at Cronbach's Alpha. Cluster analysis is also done by referring to Kannadhasan (2015) to identify the number of the Financial Risk Tolerance (FRT) category and classify the retail investors in different groups. Cluster 1 is labeled Below Average FRT and Cluster 2 is Above Average FRT. Then a test with binary logistic regression and classification table analysis is conducted.

\section{RESULTS AND DISCUSSIONS}

Table 1 show the result of the validity testing of Respondents' data.

Table 1. The result of the validity testing of Respondents' data.

\begin{tabular}{lclll}
\hline No. & Statement & Person Correlation & Sig. & Desc. \\
\hline 1 & FRT1 & $0.87^{*}$ & 0.01 & Valid \\
2 & FRT2 & $0.73^{*}$ & 0.01 & Valid \\
3 & FRT3 & $0.65^{*}$ & 0.01 & Valid \\
4 & FRT4 & $0.78^{*}$ & 0.01 & Valid \\
5 & FRT5 & $0.63^{*}$ & 0.01 & Valid \\
\hline
\end{tabular}

* Correlation is significant at the 0.01 level. FRT $=$ financial risk tolerance.

The result shows all used indicators to measure FRT variable are valid at the 0.01 level.

Table 2. The result of the reliability testing.

\begin{tabular}{llcl}
\hline No & Variable & Cronbach's Alpha & Desc. \\
\hline 1 & FRT $^{*}$ & 0.79 & Reliable \\
\hline
\end{tabular}

*FRT = financial risk tolerance.

The result shows Cronbach Alpha score of 0.788 which is above 0.6 , meaning that the data collected is reliable so that the instrument or indicator used to measure is consistent.

Table 3. The result of cluster analysis validation.

\begin{tabular}{lcc}
\hline FRT Variable & $\begin{array}{c}\text { Cluster } \\
\text { Average FRT })\end{array}$ & $\begin{array}{l}\text { Cluster } 2 \\
\text { Average FRT) }\end{array}$ \\
\hline FRT1 & $1.91(0.64)$ & $2.99(0.58)$ \\
FRT2 & $2.83(0.89)$ & $3.33(0.58)$ \\
FRT3 & $2.29(0.68)$ & $3.13(0.74)$ \\
FRT4 & $2.78(0.74)$ & $3.32(0.55)$ \\
FRT5 & $1.97(0.58)$ & $2.72(0.73)$ \\
Total Score & 11.78 & 15.49 \\
Total retail investors & 87 & 75 \\
\hline
\end{tabular}

*FRT $=$ financial risk tolerance.

It appears that the average or mean of each indicator in Cluster 1 is lower than the average or mean in Cluster 2. This indicates that members or investors who are in Cluster 1 have lower financial risk tolerance than members or investors in Cluster 2.

In table 4 above, it can be seen that the significance value is equal to 0.99 where the probability score is greater than the value of $\alpha$ which is 0.05 . As $0.99>0.05$ then $\mathrm{HO}$ is accepted where the model is enough to explain the data or model is acceptable and hypothesis testing can be done.

Table 5 shows the change of Log Likelihood -2 value from 223,690 to 212,563 and significant at the real level of $10 \%$ (sig 0.085 ) thus rejecting $\mathrm{H} 0$, which indicates that the addition of independent va- 
riable gives significant effect to the model and there is a significant influence together from the independent variable against dependent variable.

Table 4. The result of goodness of fit test

\begin{tabular}{ll}
\hline Test & Sig. \\
\hline Hosmer-Lemeshow statistic & 1.47 \\
Chi square probability & 0.99 \\
\hline
\end{tabular}

Table 5. Test results.

\begin{tabular}{llll}
\hline Model & -2 Log Likelihood & Chi square & Sig \\
\hline Intercept & 223.69 & & \\
Final & 212.56 & 11.13 & $0.09 * * *$ \\
\hline
\end{tabular}

*** significant at $\alpha=10 \%$.

Table 6 shows that only income variable that is significant at 5\% level, while variables of gender, age, material status, education, and occupation are not significant. This means that only income variable positively affects the Financial Risk Tolerance. Meanwhile, other variables have no effect on Financial Risk Tolerance.

Table 6. The result of parameter model test

\begin{tabular}{lccc}
\hline Variable & Coefficient (B) & Std. Error & Sig \\
\hline Constant & -2.87 & 1.29 & 0.02 \\
Gender & 0.50 & 0.40 & 0.20 \\
Age & 0.14 & 0.38 & 0.72 \\
Marital status & 0.60 & 0.54 & 0.27 \\
Education & -0.13 & 0.53 & 0.81 \\
Occupation & 0.28 & 0.22 & 0.21 \\
Income & 0.57 & 0.27 & $0.03 * *$ \\
$* * *$ significant at $\alpha=5 \%$. & &
\end{tabular}

The results of the study are consistent with Kannadhasan (2015) which states that individuals with higher incomes have sufficient resources to meet their basic commitments. Since investors make investments with surplus money investors have a greater capacity over the coming risk. Grable et al. (2006), Hallahan et al. (2003), Thanki (2015) also say that high-income individuals have funds to anticipate losses, resulting in risky investments. These results are also supported by the research results conducted by Sulaiman (2012) and Thanki (2015) who find that income has a positive effect on financial risk tolerance.

Pompian (2006) stated no correlation between gender variables and risk tolerance. The results are also consistent with the results of Sulaiman's (2012) study that gender variable is insignificant to risk tolerance.

Wang \& Hanna (1998) and Grable (2000), find that risk tolerance has a positive correlation with age where the older individual or investor, has greater willingness to take financial risk, but the correlation between age and risk tolerance is not always linear. Hallahan et al. (2003), Grable et al. (2006), Faff et al. (2008) affirm a negative but not linear correlation between age and risk tolerance which means that risk tolerance decreases towards age until certain point, then risk tolerance increases towards age. Some other studies such as Grable (1997), Sung \& Hanna (1996) also affirm no significant correlation between age variable and risk tolerance.

This research is consistent with the results of Kannadhasan's (2015) study which find that marital and occupational status had no significant effect on financial risk tolerance. It is also consistent with the results of research by Thanki (2015) and Hallahan et al. (2003) that education has no significant effect on financial risk tolerance.

Table 7. The result of classification table analysis

\begin{tabular}{llll}
\hline Observed & $\begin{array}{l}\text { Predicted } \\
\text { Cluster 1 }\end{array}$ & $\begin{array}{l}\text { Predicted } \\
\text { Cluster 2 }\end{array}$ & $\begin{array}{l}\text { Percent } \\
\text { Correct }\end{array}$ \\
\hline Cluster 1 & 59 & 28 & $67.8 \%$ \\
Cluster 2 & 38 & 37 & $49.3 \%$ \\
Overall percentage & & & $59.3 \%$ \\
\hline
\end{tabular}

Table 7 shows that the model prediction ability of the dependent variable is $59.3 \%$.

\section{CONCLUSION}

The result of significance test showed that the formed model is in accordance with the observed data and showed the influence of demographic factors such as gender, age, marital status, education, occupation and income to financial risk tolerance. Based on the result of parameter model test, it can be seen that the income variable has a significant positive partial influence on financial risk tolerance. These results indicate that the higher the level of income or income retail investors, the higher the financial risk tolerance or tolerance of financial risk to the investor would be. While other independent variables such as gender, age, marital status, education, and occupation show no significant partial influence on financial risk tolerance. Further research recommendation is in line with Kannadhasan (2015) that is the need of using variables other than demographic factors such as personality type, race, family background, culture, and birth order so that the research model will give better reflection on what factors influence financial risk tolerance.

\section{REFERENCES}

Chang, C.C., DeVaney, S.A., \& Chiremba, S.T. 2004. Determinants of subjective and objective risk tolerance. Journal of Personal Finance 3(3): 53-67. 
Faff, R. 2008. On the Linkage between Financial Risk Tolerance and Risk Aversion. The Journal of Financial Research 31(1): 1-23

Grable, J. E. 1997. Investor risk tolerance: testing the efficacy of demographics as differentiating and classifying factors. Unpublished Tesis. Virginia Polytechnic Institute and State University.

Grable, J. E. 2000. Financial risk tolerance and additional factors that affect risk taking in everyday money matters. Journal of Business and Psychology 14(4): 625-630.

Grable, J., Lytton, R.H., O’Neill, B., Joo, S.H., \& Klock, D. 2006. Risk tolerance, projection bias, vividness and equity prices. The Journal of Investing: 68-74.

Hallahan, T., Faff, R., \& McKenzie, M. 2003. An exploratory investigation of the relation between risk tolerance scores and demographic characteristics. Journal of Multinational Financial Management 13(4-5): 483-502.

Hanna, S.D., Gutter, M.S., \& Fan, J.X. 2001. A measure of risk tolerance based on economic theory. Financial Counseling and Planning 12(2): 53-60.

Kannadhasan, M. 2015. Retail investor' financial risk tolerance and their risk-taking behaviour: the role of demographics as differentiating and classifying Factors. IIMB Management Review 27: 175-184.

Moreschi, R.W. 2004. Incorporating investor risk tolerance into the financial planning process. Journal of Personal Finance 3: 89-98.

Pompian, M.M. 2006. Behavioral finance and wealth management: how to build optimal portfolios that account for investor biases. Canada: John Wiley \& Sons, Inc.

Sulaiman, E.K. 2012. An empirical analysis of financial risk tolerance and demographic features of individual investors. Procedia Economics and Finance: 109-115.

Sung, J. \& Hanna, S. 1996. Factors related to risk tolerance. Financial Counseling and Planning 7(1): 11-20.

Thanki, H. 2015. Risk of tolerance dependent on what? demographics or personality type: findings from an empirical research. Journal of Marketing and Consumer Research 6: 48-56.

Wang, H. \& Hanna, S. 1998. Does risk tolerance decrease with age? Financial Counseling and Planning 8(2). 